\title{
Adhesive bonding technology on the move
}

Adhesive technology is currently booming. Many even call it the joining technology of the 21st century. In any case, adhesive bonding is an important key to the development of countless innovations and is indispensable when different materials need to be joined together.

The growing importance of modern industrial adhesive bonding technology has inspired us to make "Adhesion" even more attractive by giving it a new layout. And this is the very first issue to benefit from the makeover. The content of our magazine is now fresher, clearer, more straight-forward and, we think, easier to read. But see for yourself. We hope you like the new look. Please let us know what you think, as optimising the layout of a magazine is always an ongoing process. We look forward to your constructive criticism.

The outer appearance of "Adhesion" may have changed, but not its conceptual objectives. "Adhesion" will remain what it has always been - the interface between raw material suppliers, adhesives manufacturers and users. As before, we will continue to address the very latest issues, taking into account the interests of raw material, adhesives and sealant producers on the one hand and those of processors on the other.

All these changes also apply, of course, to our interactive e-magazine, which has been available to you for some time now alongside the printed version. The e-magazine enables you, as a subscriber, to read "Adhesion" on your mobile device at any time and wherever you are. You can find a description of how it works on page 10.

I hope you enjoy reading our interesting reports, either in the printed magazine or the digital version, and as always I wish you the very best connections.

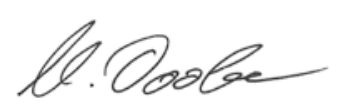

Marlene Doobe

Editor-in-Chief

marlene.doobe@springer.com 